In Strip (1) is showed the spot of ADP and A5'MP that developed as coctrol in order to ckeck the value of $R_{F}$. In Strip (2) that the enzyme fluid alone was developed, no spot is observed. In the strips (3)-(6), Spot a indicates the spot or its traces of ATP; Spot b, ADP; Spot c, A5'MP.

Fig. 3 (a) An electrophoretic pattern of crude myokinase extract of rat kidney tissues on the cellulose acetate membrane. This pattern indicates that crude myokinase extract of rat kidney tissues consists of 6 or 7 fractions of protein: A, B, C, D, E, F, (G). Ponceau 3R staining.

(b) The enzymatic activity of crude myokinase extract of rat kidney tissues on the other membrane treated on the same condition as in (a). The incubation was performed at $37.5^{\circ} \mathrm{C}$ on $\mathrm{pH} 9.5$ with the incubating medium of Padykula and Herman. The final concentrations of the substrate: ATP, $6 \mathrm{mM} ; \mathbf{A 5}^{\prime} \mathrm{MP}, 6 \mathrm{mM}$. Incubation time: 18 hours. ADP formed was detected with ultraviolet absorption $(260 \mathrm{~m} \mu)$.

The fractions $B$ and $C$ correspond to an enzymatic activity of crude myokinase extract.

\title{
Reinvestigation of Histochemical Demonstration for UDPG-pyrophosphorylase
}

\author{
Tadao TAKEUChI and Yukiharu ShIRAISHI
}

Department of Pathology, Kumamoto University School of Medicine, Kumamoto

An attempt of the histochemical demonstration of UDPG-pyrophosphorylase was first made by Takeuchi and Glenner ${ }^{1,2)}$ trying the methodology with two techniques. The one was a metal-salt method in which the lead-salt precipitates of phosphate released from glucose-1-phosphate (G-1-P) in the presence of uridine triphosphate (UTP) by the pyrophosphorylase was histochemically detected in situ, but in this case the specificity for pyrophosphorylase could not be demonstrable by the non-specific precipitation with the simultaneous release from G-1-P and UTP by phosphatases. The other was a technique for demonstrating polysaccharide synthesized from the substrate by the pyrophosphorylase through the UDPG-formation and there was a possibility of it's demonstration in this case. The newly synthesized polysaccharide might be deposited in situ and histochemically demonstrable by the iodine reaction and also by the periodic acid Schiff's reagent like the method demonstrating amylophosphorylase. However, there may be some difficulties for differentiation between two pathways of polysaccharide synthesis from G-1-P through the amylophosphorylase and through the UDPG-pyrophosphorylase system. In this paper, the histochemical differentiation for this will be presented.

\section{Materials and Methods}

Cryostat cut sections of fresh rat skeletal muscle and liver were used as 
the enzyme material. The serial sections were incubated for one hour at $37^{\circ} \mathrm{C}$ in various substrate mixtures with or without the co-factor, activators and inhibitors for amylophosphorylase and for UDPG-pyrophosphorylase respectively. The standard substrate mixture was composed of $50 \mathrm{mg} \mathrm{G}-1-\mathrm{P}, 15 \mathrm{ml}$ buffer and $10 \mathrm{ml}$ distilled water for each enzyme. $20 \mathrm{Mg}$ muscle adenylic acid (AMP) as the co-factor was added to the substrate mixture for demonstration of amylophosphorylase and $20 \mathrm{mg}$ UTP was added to the substrate mixture for UDPG-pyrophosphorylase. Sodium fluoride, cobaltous nitrate, mercury chloride, potassium periodate, potassium cyanide, magnesium chloride, phlorizin and sodium glucose-6-phosphate (G-6-P) were utilized as the inhibitors and the activators or co-factor. Acetate buffer was used at the acid range and tris-buffer at the alkaline range.

\section{Results and Discussion}

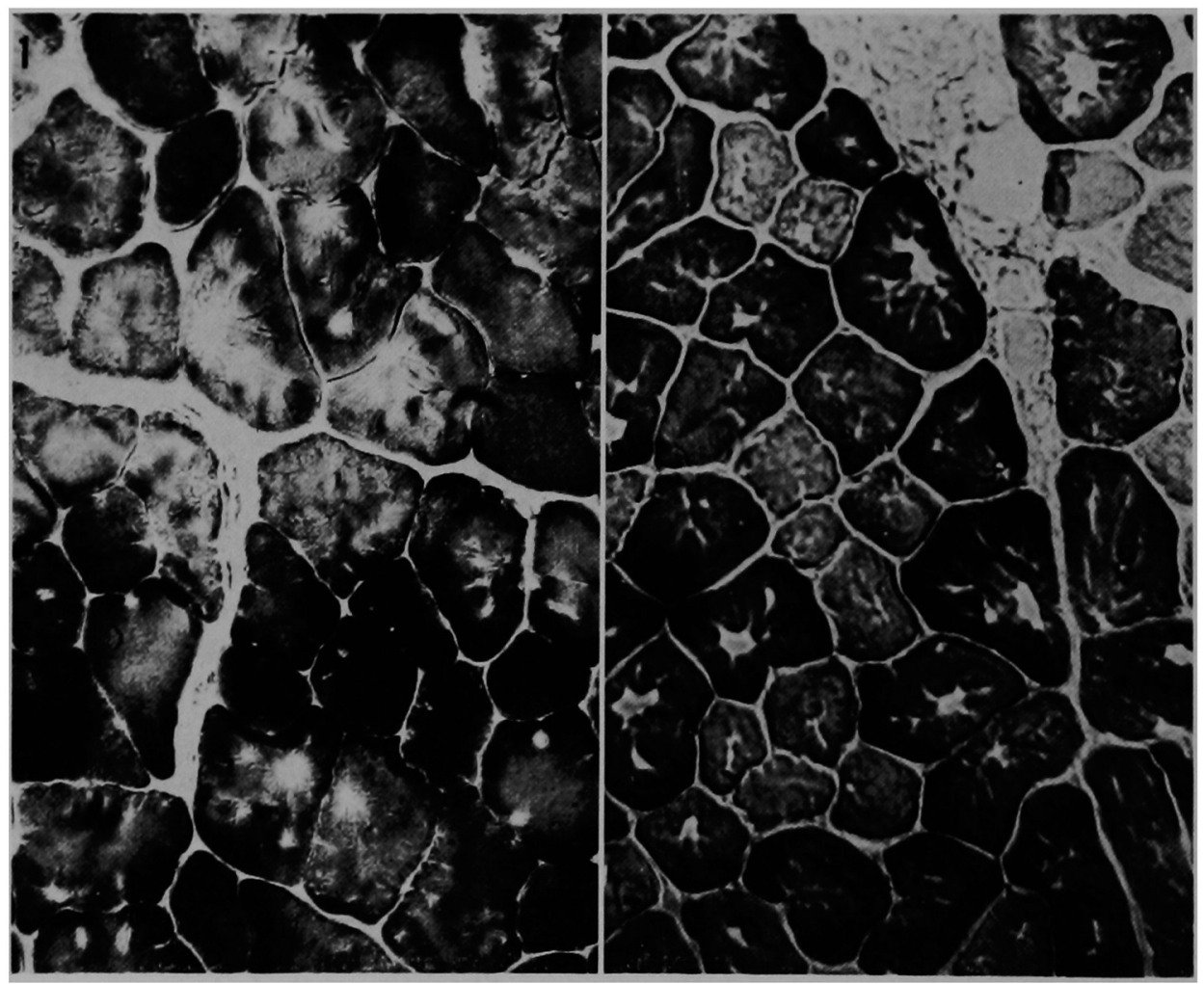

Fig. 1 Polysaccharide synthesized from the substrate mixture containing glucose-1-phosphate and UTP with cobaltous ions and phlorizin at $\mathrm{pH} 7.4$ for one hour at $37^{\circ} \mathrm{C}$ stains with iodine by the Takeuchi's method. The reaction for enzymes (probably pyrophosphorylase and glycogen synthetase system) is more predominantly demonstrated in small muscle fibers of the rat thigh muscle.

Fig. 2 Polysaccharide synthesized from the substrate mixture containing glucose-1-phosphate and muscle adenylic acid at $\mathrm{pH} 5.7$ for one hour at $37^{\circ} \mathrm{C}$ stains with the same iodine technique. The reaction for amylophosphorylase occurs more intensely in the large size fibers. 
1. Glycogen synthesis from glucose-1-phosphate at different $\mathrm{pH}$.

The polysaccharide stained blue with iodine was synthesized in the skeletal muscle fibers, particularly in white fibers of large size, more predominantly at the acid range in case of adding AMP than UTP. On the other hand, the iodine blue stained polysaccharide synthesized from G-1-P with UTP was seen in the skeletal muscle fibers more abundantly at the alkaline range. However, polysaccharide synthesis could occur even both at the alkaline and acid ranges both in cases using AMP and UTP. The distinct differentitation between two pathways through phosphorylase and pyrophosphorylase was histochemically rather difficult only by the $\mathrm{pH}$ difference. The polysaccharide synthesis from uridine-diphosphate glucose (UDPG) occurred mainly at the alkaline range and in somewhat different distribution of $\mathrm{pH}$ from the former two cases (Table 1).

Table 1. Glycogen Synthesis in Rat Skeletal Muscle at Various pH

\begin{tabular}{c|c|c|c}
\hline \multicolumn{1}{|c|}{ Substr. } & G-1-P & G-1-P, Co & UDPG \\
pH & A M P & U T P-6-P \\
\hline 4.0 & - & - & - \\
5.0 & +++ & - & - \\
5.7 & +++++ & ++ & - \\
6.2 & +++++ & +++ & +++ \\
7.0 & ++ & +++ & ++++ \\
7.4 & ++ & ++++ & ++++ \\
8.4 & - & ++ & ++ \\
\hline
\end{tabular}

The amylophosphorylase activity could be always demonstrable at the acid range by use of the substrate without UTP, and inhibited by phlorizin $(0.001 \mathrm{M})$ and cobaltous ions $(0.03 \mathrm{M})$. On the other hand, the pyrophosphorylase activity could be demonstrable and activated by cobaltous ions at the alkaline range by use of UTP (Table 2). However, the problem still remained whether polysaccharide synthesis might occur only through UDPG-pyrophosphorylase system or both through two pathways. The same result was seen in the liver tissue, except for difference of the iodine color of synthesized polysaccharide by the enzyme activity.

Table 2. Histochemical Differentiation of Glycogen Synthesis from G-1-P via Two Pathways

\begin{tabular}{l|c|c|c|c}
\multicolumn{1}{c|}{ Tissues } & \multicolumn{2}{|c|}{ Skeletal Muscle } & \multicolumn{2}{c}{ Liver Cells } \\
\hline Substrates & pH 7.4 & 5.7 & $\mathrm{pH} 7.4$ & 5.7 \\
\hline G-1-P & - & ++ & - & + \\
G-1-P, AMP & - & +++++ & - & +++ \\
G-1-P, UTP & ++ & + & ++ & + \\
G-1-P, Co, AMP, Phlorizin & + & $(+)$ & + & + \\
G-1-P, Co, UTP, Phlorizin & +++ & + & ++ & + \\
\hline
\end{tabular}


2. Effect of activators and inhibitors upon two pathways.

Glucose-6-phosphate, potassium cyanide and mercury chloride inhibited both two pathways of glycogen synthesis. Potassium periodate stimulated the polysaccharide synthesis by the phosphorylase activity and sodium fluoride intensified it indirectly by inhibition of PR-enzyme in tissue cells. Phlorizin inhibited the phosphorylase pathway. On the other hand, cobaltous nitrate stimulated considerably the synthesis from G-1-P with UTP at the alkaline range by the enzyme activities which seemed to be presumably the UDPGpyrophosphorylase system. The distinct differentiation between the histochemical demonstration for phosphorylase and that for pyrophosphorylase was also somewhat difficult only by use of activators and inhibitors (Table 3 ).

Table 3. Effect of Activators and Inhibitors upon Pyrophosphorylase and Amylophosphorylase of Rat Skeletal Muscle.

\begin{tabular}{|c|c|c|}
\hline Enzymes & $\begin{array}{l}\text { UDPG- } \\
\text { pyrophosphorylase } \\
\text { (pH 7.4) }\end{array}$ & $\begin{array}{c}\text { Amylo- } \\
\text { phosphorylase } \\
\text { (pH 5.7) }\end{array}$ \\
\hline $\begin{array}{l}\text { Effective } \\
\text { factors }\end{array}$ & $\begin{array}{c}\text { G-1-P+UTP } \\
(++)\end{array}$ & $\begin{array}{l}\text { G-1-P+AMP } \\
(t+t+t)\end{array}$ \\
\hline AMP $(0.004 \mathrm{M})$ & $+t+$ & ++++ \\
\hline G-6-P (0.003M) & - & + \\
\hline $\mathrm{NaF}(0.002 \mathrm{M})$ & ++ & $+++t+$ \\
\hline Phlorizin $(0.001 \mathrm{M})$ & ++ & $+t$ \\
\hline $\mathrm{Co}\left(\mathrm{NO}_{3}\right)_{2}(0.001 \mathrm{M})$ & +++ & + \\
\hline $\mathrm{MgCl}_{2}(0.001 \mathrm{M})$ & ++ & ++ \\
\hline $\mathrm{HgCl}_{2}(0.001 \mathrm{M})$ & + & + \\
\hline $\mathrm{KCN}(0.01 \mathrm{M})$ & - & - \\
\hline $\mathrm{KIO}_{4}(0.02 \mathrm{M})$ & ++ & $+t+t+$ \\
\hline
\end{tabular}

Incubation for 1 hour at $37^{\circ} \mathrm{C}$

3. Histochemical difference between amylophosphorylase and pyrophospho. rylase.

The amylophosphorylase activity was histochemically easily demonstrable by use of the substrate mixture containing G-1-P without UTP at pH 5.7 and

Table 4. Histochemical Difference between UDPG-Pyrophosphorylase and Amylophosphorylase

\begin{tabular}{l|c|c}
\multicolumn{1}{c}{ Enzymes } & $\begin{array}{c}\text { UDPG- } \\
\text { Conditions }\end{array}$ & $\begin{array}{c}\text { Amylo- } \\
\text { phosphorylase }\end{array}$ \\
\hline Substrate & UTP, G-1-P & G-1-P \\
Co-factor & 7.4 & AMP \\
Optimal pH & No influence & 5.7 \\
PR-enzyme & No influence & Inactivation \\
Na F & No influence & inhibition \\
Phlorizin & activation & inhibition \\
$\mathrm{Co}^{++}$ & &
\end{tabular}


it was stimulated by AMP, activated indirectly by fluoride and inhibited by phlorizin and cobaltous ions. On the contrary, it seemed to be considerably difficult to demonstrate histochemically the UDPG-pyrophosphorylase activity even by use of UTP, because polysaccharide synthesis from G-1-P through the phosphorylase system might be not completely denied under such condition. It was, however, not considered that no UDPG-pyrophosphorylase activity might be histochemically demonstrable, because the cobaltous ions activated intensely the pyrophosphorylase activity and inhibited the phosphorylase. It was also refered to the differentiation to find the fact that phlorizin and sodium fluoride has no influence upon the pyrophosphorylase activity contrary to the amylophosphorylase activity.

In this way, the histochemical differentiation between two pathways of glycogen synthesis from G-1-P through UDPG-pyrophosphorylase and amylophosphorylase was found to be possible (Table 4).

\section{Summary}

The histochemical demonstration of UDPG-pyrophosphorylase may be possible by use of polysaccharide synthesis from glucose-1-phosphate with uridine triphosphate by the enzyme activity under the suitable conditions combining $\mathrm{pH}$, co-factor, activators and inhibitors, in spite of the difficult differentiation from amylophosphorylase. However, the distinct differentiation between two pathways still remains in difficulty.

\section{Reference}

1) Takeuchi, T. and Glenner, G.G. J. Histochem. Cytochem. 9(6); 623-624, 1961. Takeuchi, T. Ann. Histochem. 7; 61-80, 1962.

\section{Acknowledgment}

The authors wish to express their appreciation to Dr. Glenner in NIH, U.S.A. for his kind help, particularly to get UTP and UDPG. 